Article

\title{
Improving of Sensitivity of PbS Quantum Dot Based SWIR Photodetector Using P3HT
}

\author{
Kyeong-Ho Seo ${ }^{1}$, Jaewon Jang ${ }^{1,2} \mathbb{D}$, In Man Kang ${ }^{1,2}$ and Jin-Hyuk Bae ${ }^{1,2, * \mathbb{C}}$ \\ 1 School of Electronic and Electrical Engineering, Kyungpook National University, Daegu 41566, Korea; \\ tjrudgh0826@naver.com (K.-H.S.); j1jang@knu.ac.kr (J.J.); imkang@ee.knu.ac.kr (I.M.K.) \\ 2 School of Electronics Engineering, Kyungpook National University, Daegu 41566, Korea \\ * Correspondence: jhbae@ee.knu.ac.kr; Tel.: +82-53-950-7222
}

check for updates

Citation: Seo, K.-H.; Jang, J.; Kang,

I.M.; Bae, J.-H. Improving of

Sensitivity of PbS Quantum Dot

Based SWIR Photodetector Using

P3HT. Materials 2021, 14, 1488.

https://doi.org/10.3390/ma14061488

Academic Editors: Antonio Polimeni and Wiesław Stręk

Received: 8 January 2021

Accepted: 16 March 2021

Published: 18 March 2021

Publisher's Note: MDPI stays neutral with regard to jurisdictional claims in published maps and institutional affiliations.

Copyright: (C) 2021 by the authors. Licensee MDPI, Basel, Switzerland. This article is an open access article distributed under the terms and conditions of the Creative Commons Attribution (CC BY) license (https:/ / creativecommons.org/licenses/by/ $4.0 /)$.
Abstract: In this study, we improved the photosensitivity of the lead sulfide quantum dot (PbS QD)-based shortwave infrared (SWIR: 1.0-2.5 $\mu \mathrm{m}$ ) photodetector by blending poly(3-hexylthiophene2,5-diyl) (P3HT) with PbS QD. The PbS QD used for SWIR photoactive layer showed an absorption peak at $1410 \mathrm{~nm}$. In addition, by using zinc oxide nanoparticles (ZnO NPs) as an interlayer, we obtained the stable current characteristics of our device. To confirm the effectiveness of P3HT on the PbS QD-based SWIR photodetector, we compared the electrical characteristics of a PbS QD-based device with a hybrid P3HT:PbS QD-based device. In the reverse bias region, the current on/off ratio of the PbS QD-based device was 1.3, whereas the on/off ratio of the hybrid P3HT:PbS QD-based device was 2.9; 2.2 times higher than the PbS QD-based device. At $-1 \mathrm{~V}$, the on/off ratio of the PbS QD-based device was 1.3 and the on/off ratio of the hybrid P3HT:PbS QD-based device was 3.4; 2.6 times higher than the PbS QD-based device. The fabricated P3HT:PbS QD-based device had the highest on/off ratio when $-1 \mathrm{~V}$ voltage was applied.

Keywords: photosensitivity; poly(3-hexylthiophene-2,5-diyl); lead sulfide quantum dots; shortwave infrared photodetector; current on/off ratio

\section{Introduction}

Shortwave infrared (SWIR: 1.0-2.5 $\mu \mathrm{m}$ ) photodetectors are widely used in various fields such as telecom, temperature measurement, remote sensing, and spectroscopy [1-4]. In general, compound semiconductors, such as InGaAs, InAs, are applied to the fabrication of SWIR photodetectors. However, these materials require molecular beam epitaxial process to grow which have the high fabrication cost and difficulty of large-scale production $[5,6]$. To overcome these difficulties, many researchers have paid attention to lead sulfide quantum dots ( $\mathrm{PbS} \mathrm{QDs}$ ), another SWIR active material, due to cost-effectiveness and large-scale manufacturability [7]. Furthermore, PbS QDs have the advantages of having high stability in air, size tunability, and flexible substrate compatibility [8-11], so this material emerges as a promising candidate for SWIR detection.

To date, the Schottky structure of indium tin oxide (ITO)/ $\mathrm{PbS} \mathrm{QD} /$ aluminum (Al) is one of the most commonly used structures $[12,13]$. However, the ITO/PbS QD/Al structure is reported to have poor performance due to bad rectification characteristics $[14,15]$. To overcome this drawback, zinc oxide nanoparticles ( $\mathrm{ZnO} N P s)$ were used as an interlayer between $\mathrm{PbS}$ QDs and $\mathrm{Al}$, preventing the $\mathrm{Al}$ diffusion and stabilizing the $\mathrm{PbS} \mathrm{QD}$ layer $[14,16]$. ZnO NPs are one of the n-type semiconducting materials that have good transparency, wide bandgap of $3.37 \mathrm{eV}$, and good electron mobility characteristics [17,18]. Kwon et al. fabricated a PbS QD-based uncooled SWIR photodetector with stable current characteristics by using a $\mathrm{ZnO}$ NP interlayer.

Over the past few decades, $\mathrm{PbS}$ QDs have been used in optoelectronic devices along with conjugated polymers. A conjugated polymer is an organic material that has the advantage of flexibility, lightweight, low cost, and large-scale manufacturability [19,20]. 
Among the numerous conjugated polymers, poly(3-hexylthiophene-2,5-diyl) (P3HT) is one of the most widely used p-type semiconducting polymers [21]. In addition, it is relatively stable, has high hole mobility, and provides a shorter hole extraction time as a hole transport layer [22,23], contributing to improving the electrical conductivity of the electronic devices. A hybrid P3HT:PbS QD nanocomposite has the advantages of both P3HT and PbS QD and is still widely used in photodetectors and photovoltaics [24-26]. $\mathrm{Xu}$ et al. showed the operating mechanism of a hybrid P3HT:PbS QD-based device via energy level diagrams. In the literature, the highest occupied molecular orbital (HOMO) gap between PbS QD $(-5.1 \mathrm{eV})$ and $\mathrm{P} 3 \mathrm{HT}(-4.9 \mathrm{eV})$ is very narrow, enabling efficient hole transport. Such proper use of these donor-acceptor materials can expect the optimal photogenerated charge separation, contributing to improving the photosensitivity of the electronic devices $[25,27]$.

Based on these backgrounds, this study focused on the photosensitivity improvement of the PbS QD-based SWIR photodetector with or without P3HT. A blending of P3HT and $\mathrm{PbS}$ QD contributed to the improvement of electrical characteristics by providing the optimal photogenerated charge separation condition. The photosensitivity evaluation was specifically quantified through the current on/off ratio. These results showed that the use of an optimized donor/acceptor had a positive effect on the performance of the $\mathrm{PbS}$ QD-based SWIR photodetector.

\section{Materials and Methods}

\subsection{Fabrication of the Hybrid P3HT:PbS QD Solution}

Prior to preparing the hybrid P3HT:PbS QD solution, we synthesized the PbS quantum dots. A 1 mmol amount of lead chloride $\left(\mathrm{PbCl}_{2}, 99.999 \%\right.$, Sigma-Aldrich, St. Louis, $\mathrm{MO}$, USA) was dissolved in $5 \mathrm{~mL}$ of oleylamine (OLA, 70\%, Sigma-Aldrich, St. Louis, MO, USA) under $\mathrm{N}_{2}$ conditions for $30 \mathrm{~min}$ at room temperature. Then, the dissolved solution was heated to $160{ }^{\circ} \mathrm{C}$ for $1 \mathrm{~h}$. The heated solution was then cooled to $120{ }^{\circ} \mathrm{C}$ for $15 \mathrm{~min}$. During the cooling process, a three-neck flask was sealed to hold the vacuum condition. After $15 \mathrm{~min}$, the three-neck flask was opened, and $\mathrm{N}_{2}$ gas was reinjected. While the $\mathrm{PbCl}_{2}$-OLA suspension was prepared, $0.36 \mathrm{mmol}$ of sulfur (S, 99.998\%, Sigma-Aldrich, St. Louis, MO, USA) was dissolved in $1 \mathrm{~mL}$ of OLA at room temperature under $\mathrm{N}_{2}$ conditions. The prepared sulfur stock solution was quickly injected into the $\mathrm{PbCl}_{2}$-OLA suspension under stirring, and the stirring continued for an additional $30 \mathrm{~min}$ at $150^{\circ} \mathrm{C}$. The resultant was rinsed with ethyl alcohol (EtOH, 99.9\%, Samchun Pure Chemical CO., Ltd., Seoul, Korea), then centrifuged, precipitated, and dispersed with toluene $(99.8 \%$, Sigma-Aldrich, St. Louis, MO, USA) at a concentration ratio of $30 \mathrm{mg} / \mathrm{mL}$. Based on the synthesized PbS QDs, we fabricated the hybrid P3HT:PbS QD solution. P3HT (5 mg) was dissolved in the $1 \mathrm{~mL}$ of PbS quantum dots for $1 \mathrm{~h}$ on a hot plate at $20^{\circ} \mathrm{C}$, and the color of the solution changed from black to maroon. Figure 1 shows the fabrication process of the hybrid P3HT:PbS QD solution.

(a)

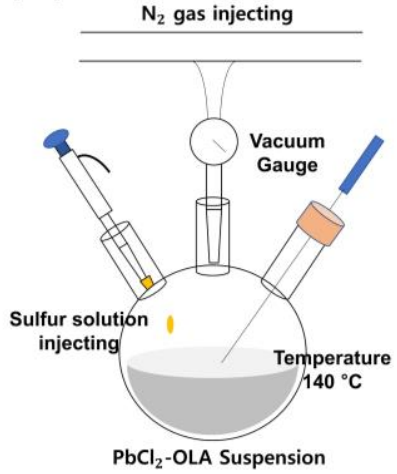

(b)

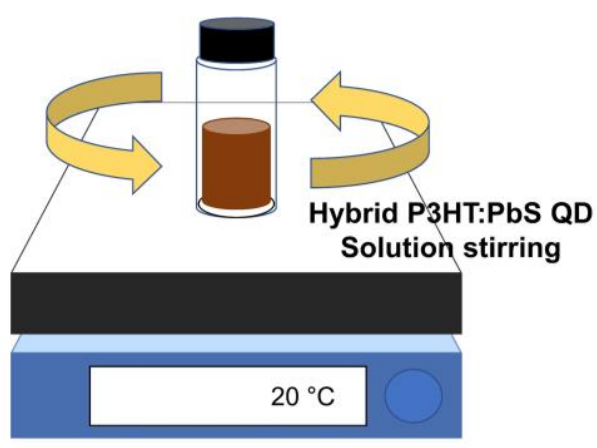

Figure 1. (a) Schematic diagram of PbS quantum dots synthesis process and (b) the fabrication process of hybrid P3HT:PbS QD solution. 


\subsection{Synthesis of $\mathrm{ZnO} N P s$}

A $2.46 \mathrm{~g}$ amount of zinc acetate dihydrate $\left(\mathrm{Zn}\left(\mathrm{CH}_{3} \mathrm{COO}\right)_{2} 2 \mathrm{H}_{2} \mathrm{O}, 98 \%\right.$, Sigma-Aldrich, USA) was dissolved in $110 \mathrm{~mL}$ of methyl alcohol (MeOH, 99.9\%, Duksan Pharmaceutical CO., Ltd., Seoul, Korea) and $1.152 \mathrm{~g}$ of potassium hydroxide $(\mathrm{KOH}, 90 \%$, Sigma-Aldrich, USA) was dissolved in $60 \mathrm{~mL}$ of $\mathrm{MeOH}$ at $60^{\circ} \mathrm{C}$ for $1 \mathrm{~h}$. The dissolved $\mathrm{KOH}$ solution was injected into the $\mathrm{ZnAc}$ solution at a rate of $(1 \mathrm{~mL} / \mathrm{s})$ and dissolved for $1 \mathrm{~h}$. The resultant was rinsed with isopropyl alcohol (IPA, 99.9\%, Duksan Pharmaceutical CO., Ltd., Korea) and hexane (95\%, Duksan Pharmaceutical CO., Ltd., Korea) mixed together and then stored for $24 \mathrm{~h}$ in a $5{ }^{\circ} \mathrm{C}$ refrigerated reagent cabinet. The precipitate was centrifuged at $3000 \mathrm{rpm}$ and dispersed with ethyl alcohol (EtOH, 99.9\%, Samchun Pure Chemical CO., Ltd., Seoul, Korea) at $30 \mathrm{mg} / \mathrm{mL}$ of concentration ratio. Figure 2 shows a schematic diagram of the synthesis process of $\mathrm{ZnO}$ nanoparticles.

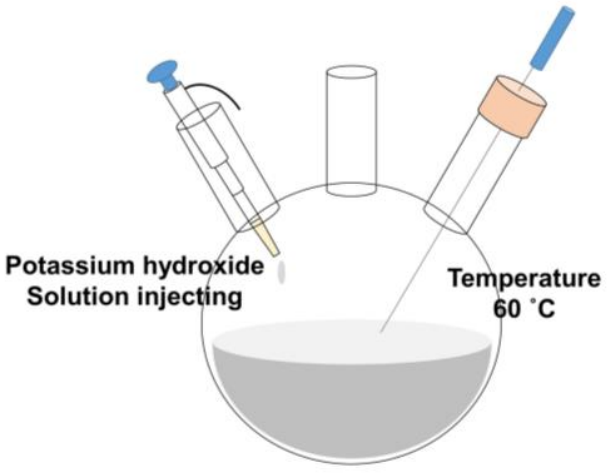

ZnAc-MeOH Suspension

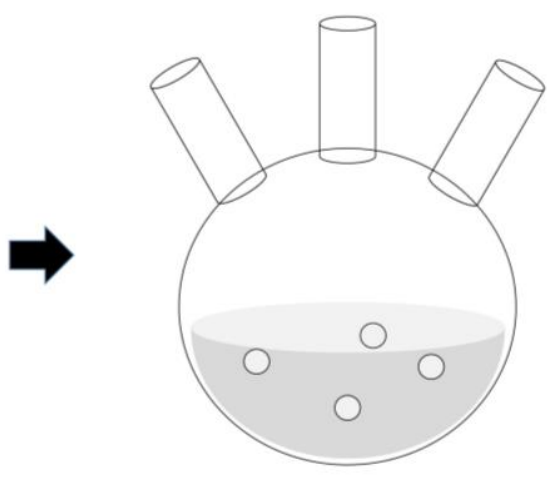

ZnO Nanoparticles Solution

Figure 2. Schematic diagram of $\mathrm{ZnO}$ nanoparticle synthesis process.

\subsection{Fabrication of the SWIR Photodetector}

All devices were fabricated through the spin-coating method. The anode was ITO, a transparent electrode, which was patterned on a $30 \mathrm{~mm} \times 30 \mathrm{~mm}$ glass substrate. The glass substrate was rinsed with acetone (99.9\%, Duksan Pharmaceutical CO., Ltd., Ansan, Korea), methanol, and isopropyl alcohol in an ultrasonic cleaner (NXPC-2010, Kodo Technical Research Co., Ltd., Gyeonggi-do, Korea) for $10 \mathrm{~min}$ sequentially to remove organic residues and impurities. To remove the residual solvent, the rinsed glass was dried under $\mathrm{N}_{2}$ gas and heat-treated on a hot plate at $150{ }^{\circ} \mathrm{C}$ for $5 \mathrm{~min}$. A UV ozone treatment was performed for $20 \mathrm{~min}$ to make the substrate hydrophilic by controlling the surface energy. Both photoactive layers, the pure PbS QD solution, and the hybrid P3HT:PbS QD solution were dispensed on the ITO glass substrate and spin-coated at $3000 \mathrm{rpm}$, respectively. Both spin-coated photoactive layers were annealed for $30 \mathrm{~min}$ in a vacuum oven at $110{ }^{\circ} \mathrm{C}$ for activation. Then, the $\mathrm{ZnO}$ NP layer used as an electron transport layer was dispensed on the formed photoactive layer, spin-coated at $1500 \mathrm{rpm}$, and then annealed at $90{ }^{\circ} \mathrm{C}$ for $30 \mathrm{~min}$. Finally, aluminum was deposited as a cathode of the device to a thickness of $150 \mathrm{~nm}$ by thermal evaporation. In the completed device, the anode and cathode cross-contact area were $9 \mathrm{~mm}^{2}$ where the device is activated. Figure 3 shows the schematic diagram of the fabricated devices, Figure 3a shows the structure of the fabricated PbS QD-based structure, and Figure $3 \mathrm{~b}$ shows the bandgap of the fabricated PbS QD-based device. When light irradiates the PbS QD-based device, electron-hole pairs (EHP) are generated within the device, then the generated EHPs are extracted to both electrodes while the external electric field was applied to the device. Figure $3 \mathrm{c}$ shows the structure of the fabricated hybrid P3HT:PbS QD-based device and Figure 3d shows the bandgap structure of the fabricated P3HT:PbS QD-based device. Unlike Figure 3b, PbS QD was blended with P3HT, so the bandgap of $\mathrm{P} 3 \mathrm{HT}$ overlapped with $\mathrm{PbS}$ QD. By overlapping the bandgap, holes generated by light in the PbS QD can be quickly extracted to the ITO electrode through the P3HT $[24,28]$. 
(a)

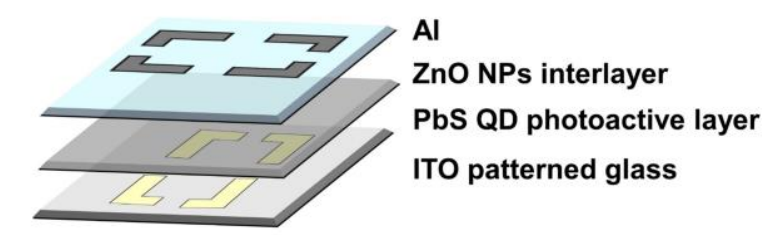

(c)

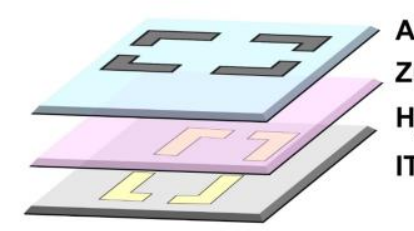

(b)

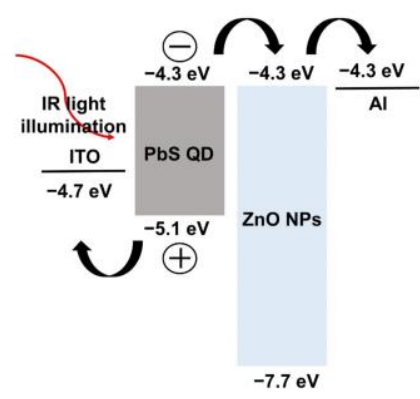

(d)

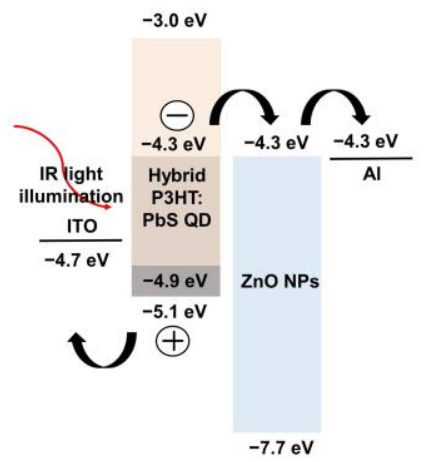

Figure 3. Schematic diagram of fabricated devices: (a) The structure of the PbS QD-based device, (b) the bandgap of the P3HT:PbS QD-based device, (c) the structure of the hybrid P3HT:PbS QD-based device and (d) the bandgap of the hybrid P3HT:PbS QD-based device.

\subsection{Measurements}

The characteristics of the synthesized PbS QD and ZnO NPs were measured using a UV-VIS-NIR spectrometer (Cary 5000, Agilent Tech., Santa Clara, CA, USA). We have been able to confirm the properties of the synthesized nanoparticles through the absorption spectrum. For the synthesized PbS QD, about $80 \%$ of toluene was injected into the cuvette to set a reference for the sample. For the synthesized $\mathrm{ZnO}$ NPs, about $80 \%$ of the synthesized $\mathrm{ZnONPs}$ were injected. The characteristics of the fabricated photodetectors were confirmed by I-V characteristics. All fabricated devices were measured in the darkroom to block external light. The IR light source was Deuterium-Halogen Light Source (SL5, StellarNet, Inc., Tampa, FL, USA). The light intensity was $1 \mathrm{~W} / \mathrm{cm}^{2}$, which provided a $2500 \mathrm{~nm}$ wavelength. To measure the I-V characteristics of the fabricated photodetector, we used the M6100 OLED I-V-L Test System (McScience, Yeongtong, Suwon, Korea) and the source meter (Keithley 2400, Tektronix, Inc., Beaverton, OR, USA).

\section{Result and Discussion}

The characteristics of the synthesized PbS QD and ZnO NPs were confirmed using a UV-VIS-NIR spectrometer. Figure 4a shows the absorption spectrum of the synthesized PbS QD; it exhibited an absorption spectrum wavelength of $1600 \mathrm{~nm}$. At $1410 \mathrm{~nm}$ wavelength, an absorption peak appeared. This means that our synthesized PbS QD absorbed $1410 \mathrm{~nm}$ of light, which is the SWIR region. When the photons struck the semiconductor, the electrons in the valence band excite into the conduction band and then formed the excitons. These excitons underwent a charge separation process and contributed to the improvement of the photoconductivity of the device.

$\mathrm{ZnO}$ NPs are wide bandgap of $3.37 \mathrm{eV}$ metal oxides that absorb ultraviolet (UV) light. Although these materials do not absorb IR light, absorbance measurements were performed to confirm our ZnO NPs were successfully synthesized. Figure $4 \mathrm{~b}$ shows the absorption spectrum of synthesized ZnO NPs. The synthesized ZnO NPs exhibited an absorption spectrum wavelength of $600 \mathrm{~nm}$. The absorption peak appeared at $325 \mathrm{~nm}$ wavelength. It means that our synthesized ZnO NPs absorbed $325 \mathrm{~nm}$ of light, and then exciton formed. However, these excitons generated by ultraviolet light were not related 
to the photoconductivity of the device. As our synthesized ZnO NPs showed a light absorption peak at $325 \mathrm{~nm}$, it was confirmed that there were no functional problems in the synthesized $\mathrm{ZnO}$ NPs. Although Figure $4 \mathrm{~b}$ did not show the parameter of electron transport, it showed that $\mathrm{ZnO}$ NPs were properly synthesized, so our synthesized $\mathrm{ZnO}$ NPs were used as a device interlayer.

(a)

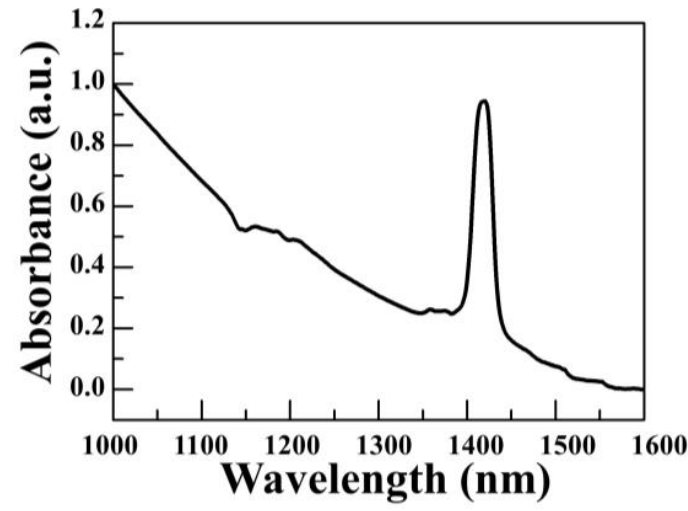

(b)

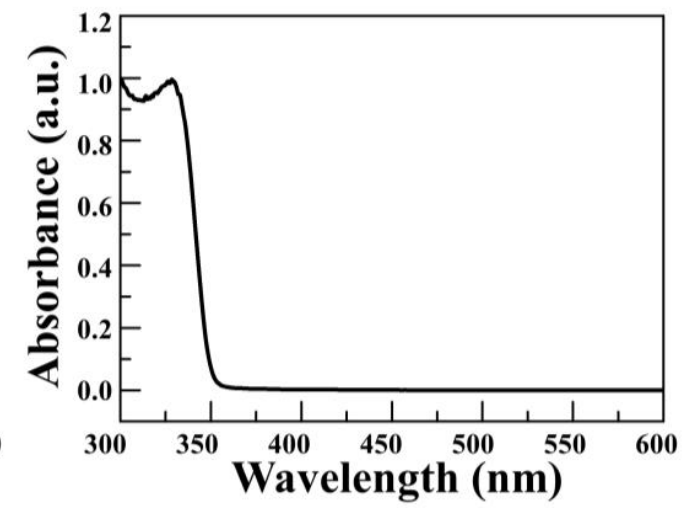

Figure 4. Absorbance spectrum of synthesized nanoparticles: (a) PbS quantum dot and (b) $\mathrm{ZnO}$ nanoparticles.

Based on these synthesized PbS QD and ZnO NPs, a SWIR photodetector was fabricated and confirmed the electrical performance of devices with or without P3HT. The $\mathrm{I}-\mathrm{V}$ characteristics of each fabricated devices with or without light illumination were measured and the current on/off ratio was calculated to determine the current change of the fabricated devices. "Light off" means the current when the device was not illuminated with IR light, while "Light on" means the current when the device was illuminated with IR light. By dividing the on current by the off current, we confirmed the change ratio of both currents. The voltage was applied from $-3 \mathrm{~V}$ to $3 \mathrm{~V}$, and the step voltage was set to $0.5 \mathrm{~V}$. Figure 5 shows the I-V characteristics of the fabricated devices.

(a)

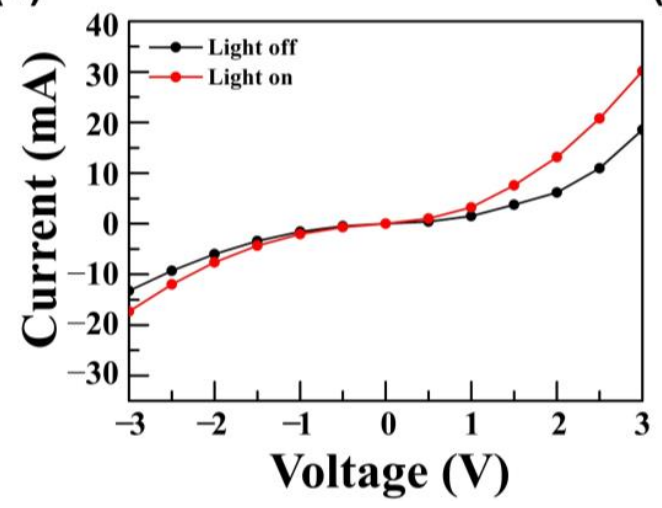

(b)

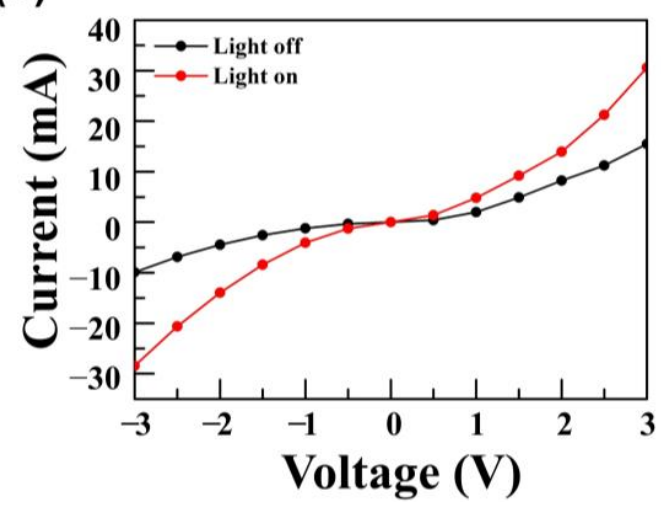

Figure 5. I-V characteristics of fabricated SWIR photodetector: (a) PbS QD-based device and (b) hybrid P3HT:PbS QD-based device.

In the reverse bias region, for the PbS QD-based device without $\mathrm{P} 3 \mathrm{HT}$, the dark current was $-13.3 \mathrm{~mA}$, the light current was $-17.6 \mathrm{~mA}$, and the current on/off ratio was 1.3 . On the other hand, for the hybrid P3HT:PbS QD-based device, the dark current was $-9.9 \mathrm{~mA}$, the light current was $-28.5 \mathrm{~mA}$, and the current on/off ratio was 2.9. Notably, the current on/off ratio of the hybrid P3HT:PbS QD-based device was about 2.2 times higher than the current on/off ratio of the PbS QD-based device [25,29]. The P3HT was considered to improve the conductivity of the photogenerated charge from $\mathrm{PbS} Q \mathrm{QD}$, resulting from 
a higher light current of the fabricated PbS QD-based SWIR photodetector. Moreover, by blending P3HT and PbS QD, the photogenerated charge separation was more efficient than $\mathrm{PbS}$ QD only device, resulting in the improvement of the photosensitivity [27]. The HOMO level of P3HT $(-4.9 \mathrm{eV})$ adjacent to the PbS QD $(-5.1 \mathrm{eV})$ provided optimal conditions for this charge separation [24]. Moreover, the current on/off ratio was the highest in which the applied voltage was $-1 \mathrm{~V}$. In the PbS QD-based device, the dark current was $-1.6 \mathrm{~mA}$, the light current was $-2.1 \mathrm{~mA}$, and the current on/off ratio was 1.3. In the P3HT:PbS QD-based device, the dark current was $-1.2 \mathrm{~mA}$, the light current was $-4.1 \mathrm{~mA}$, and the current on/off ratio was 3.4. The results obtained from the devices are shown in Table 1.

Table 1. The results of the measured devices.

\begin{tabular}{ccc}
\hline Properties & PbS QD & Hybrid P3HT:PbS QD \\
& From $-\mathbf{3} \mathbf{~ V ~ t o ~}-\mathbf{1 ~ V}$ & From $-\mathbf{3}$ V to $-\mathbf{1 ~ V}$ \\
\hline Dark current $(\mathrm{mA})$ & From -13.3 to -1.6 & From -9.9 to -1.2 \\
Light current $(\mathrm{mA})$ & From -17.6 to -2.1 & From -28.5 to -4.1 \\
On/off ratio & From 1.3 to 1.3 & From 2.9 to 3.4 \\
\hline
\end{tabular}

The structure of the fabricated hybrid P3HT:PbS QD-based device was shown through the FE-SEM image. Figure 6 shows the FE-SEM image of the fabricated hybrid P3HT:PbS QD-based device. The ITO electrode was $163 \mathrm{~nm}$, the hybrid P3HT:PbS QD layer was $51.5 \mathrm{~nm}$, the $\mathrm{ZnO}$ NP layer was $23.8 \mathrm{~nm}$ and the Al electrode was $137 \mathrm{~nm}$. Since orthogonal solvents were used in the device fabrication process, as shown in Figure 4, each layer could be deposited independently.

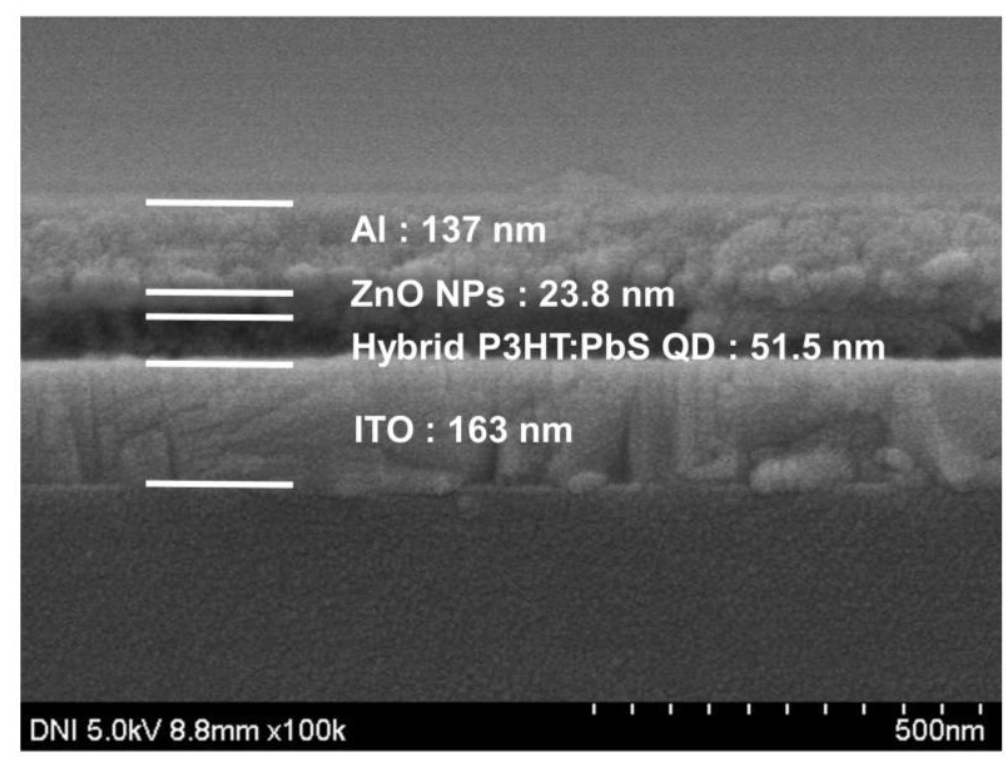

Figure 6. FE-SEM image of fabricated hybrid P3HT:PbS QD-based device.

\section{Conclusions}

In this study, we improved the photosensitivity of the SWIR photodetector based on $\mathrm{PbS}$ QD by using P3HT. To detect SWIR, we used a synthesized PbS QD with an excitonic peak at $1410 \mathrm{~nm}$. Additionally, we used ZnO NPs as an interlayer to maintain stable current characteristics. In the reverse bias region, for the PbS QD-based device without P3HT, the dark current was $-13.3 \mathrm{~mA}$, the light current was $-17.6 \mathrm{~mA}$, and the current on/off ratio was 1.3. For the hybrid P3HT:PbS QD-based device, the dark current was $-9.9 \mathrm{~mA}$, the light current was $-28.5 \mathrm{~mA}$, and the current on/off ratio was 2.9. The current on/off ratio of the hybrid P3HT:PbS QD-based device was 2.2 times higher than the PbS QD-based device. At $-1 \mathrm{~V}$, the current on/off ratio of the PbS QD-based device was 1.3, and the 
hybrid P3HT:PbS QD was 3.4, the highest among the measured currents. These results will contribute toward developing the next-generation electronic device industry by obtaining SWIR optoelectronic device performance enhancement technology.

Author Contributions: Conceptualization, K.-H.S. and J.-H.B.; Methodology, K.-H.S.; Validation, J.-H.B., J.J., I.M.K.; Formal analysis, K.-H.S.; Investigation, K.-H.S.; J.-H.B.; Data curation, K.-H.S. Writing-Original Draft Preparation, K.-H.S.; Writing—review \& editing, J.J., I.M.K., J.-H.B.; Visualization, K.-H.S.; Supervision, J.-H.B.; Project administration, J.-H.B.; Funding acquisition, J.-H.B. All authors have read and agreed to the published version of the manuscript.

Funding: This research was supported by Basic Science Research Program through the National Research Foundation of Korea (NRF) funded by the Ministry of Science and ICT (2018R1A2B6008815), and also by the BK21 Plus project funded by the Ministry of Education, Korea (21A20131600011).

Institutional Review Board Statement: Not applicable.

Informed Consent Statement: Not applicable.

Data Availability Statement: The data presented in this study are available on request from the corresponding author.

Conflicts of Interest: There are no conflicts of interest to declare. The funders had no role in the design of the study; in the collection, analyses, or interpretation of data; in the writing of the manuscript, or in the decision to publish the results.

\section{References}

1. Qiu, X.; Wang, Z.; Hou, X.; Yu, X.; Yang, D. Visible-blind short-wavelength infrared photodetector with high responsivity based on hyperdoped silicon. Photon. Res. 2019, 7, 351-358. [CrossRef]

2. Usamentiaga, R.; Venegas, P.; Guerediaga, J.; Vega, L.; Molleda, J.; Bulnes, F.G. Infrared Thermography for Temperature Measure ment and Non-Destructive Testing. Sensors 2014, 14, 12305-12348. [CrossRef] [PubMed]

3. Dehzangi, A.; McClintock, R.; Haddadi, A.; Wu, D.; Chevallier, R.; Razeghi, M. Type-II superlattices base visible/extended short-wavelength infrared photodetectors with a bandstructure-engineered photo-generated carrier extractor. Sci. Rep. 2019, 9, 5003. [CrossRef]

4. Zaini, N.; Van der Meer, F.; Van Ruitenbeek, F.; De Smeth, B.; Amri, F.; Lievens, C. An Alternative Quality Control Technique for Mineral Chemistry Analysis of Portland Cement-Grade Limestone Using Shortwave Infrared Spectroscopy. Remote Sens. 2016, 8 , 950. [CrossRef]

5. Lim, L.W.; Patil, P.; Marko, I.P.; Clarke, E.; Sweeney, S.J; Ng, J.S.; David, J.P.R.; Tan, C.H. Electrical and optical characterization of low temperature grown InGaAs for photodiode applications. Semicond. Sci. Technol. 2020, 35, 095031. [CrossRef]

6. Chen, Y.; Liu, J.; Zhao, Y.; Teng, Y.; Hao, X.; Li, X.; Zhu, H.; Zhu, H.; Wu, Q.; Huang, Y. MOCVD growth of InAs/GaSb type-II superlattices on InAs substrates for short wavelength infrared detection. Infrared Phys. Technol. 2020, 105, 103209. [CrossRef]

7. Lee, J.W.; Kim, D.Y.; So, F. Unraveling the Gain Mechanism in High Performance Solution-Processed PbS infrared PIN Photodiodes. Adv. Funct. Mater. 2015, 25, 1233-1238. [CrossRef]

8. Moreels, I.; Justo, Y.; Geyter, B.D.; Haustraete, K.; Martins, J.C.; Hens, Z. Size-Tunable, Bright, and Stable PbS Quantum Dots: A Surface Chemistry Study. ACS Nano 2011, 5, 2004-2012. [CrossRef]

9. Zhao, H.; Chaker, M.; Wu, N.; Ma, D. Towards controlled synthesis and better understanding of highly luminescent PbS/CdS core/shell quantum dots. J. Mater. Chem. 2011, 21, 8898. [CrossRef]

10. Tavakoli, M.M.; Gharahcheshmeh, M.H.; Moody, N.; Bawendi, M.G.; Gleason, K.K.; Kong, J. Efficient, Flexible, and UltraLightweight Inverted PbS Quantum Dots Solar Cells on All-CVD-Growth of Parylene/Graphene/oCVD PEDOT Substrate with High Power-per-Weight. Adv. Mater. Interfaces 2020, 7, 2000498. [CrossRef]

11. Moreels, I.; Lambert, K.; Smeets, D.; Muynck, D.D.; Nollet, T.; Martins, J.C.; Vanhaecke, F.; Vantomme, A.; Delerue, C.; Allan, G.; et al. Size-Dependent Optical Properties of Colloidal PbS Quantum Dots. ACS Nano 2009, 3, 3023-3030. [CrossRef] [PubMed]

12. Saran, R.; Curry, R.J. Lead sulphide nanocrystal photodetector technologies. Nat. Photonics 2016, 10, 81-92. [CrossRef]

13. Yang, G.; Zhu, Y.; Huang, J.; Xu, X.; Cui, S.; Lu, Z. Hole transport layer selection toward efficient colloidal PbS quantum dot solar cells. Opt. Express 2019, 27, A1338-A1349. [CrossRef] [PubMed]

14. Lai, L.H.; Speirs, M.J.; Chang, F.K.; Piveteau, L.; Kovalenk, M.V.; Chen, J.S.; Wu, J.J.; Loi, M.A. Increasing photon absorption and stability of PbS quantum dot solar cells using a ZnO interlayer. Appl. Phys. Lett. 2015, 107, 183901. [CrossRef]

15. Tang, J.; Wang, X.; Brzozowski, L.; Barkhouse, D.A.R.; Debnath, R.; Levina, L.; Sargent, E.H. Schottky Quantum Dot Solar Cells Stable in Air under Solar Illumination. Adv. Mater. 2010, 22, 1398-1402. [CrossRef] [PubMed]

16. Kwon, J.; Kim, S.; Lee, J.; Park, C.; Kim, O.; Xu, B.; Bae, J.; Kang, S. Uncooled Short-Wave Infrared Sensor Based on PbS Quantum Dots Using ZnO NPs. Nanomaterials 2019, 9, 926. [CrossRef] [PubMed] 
17. Kumar, S.S.; Venkateswarlu, P.; Rao, V.R.; Rao, G.N. Synthesis, characterization and optical properties of zinc oxide nanoparticles. Int. Nano. Lett. 2013, 3, 30. [CrossRef]

18. Pan, Y.J.; Chen, J.; Huang, Q.; Khan, Q.; Liu, X.; Tao, Z.; Zhang, Z.; Lei, W.; Nathan, A. Size Tunable ZnO Nanoparticles to Enhance Electron Injection in Solution Processed QLEDs. ACS Photonics 2016, 3, 215-222. [CrossRef]

19. Mammeri, F.; Bourhis, E.L.; Rozes, L.; Sanchez, C. Mechanical properties of hybrid organic-inorganic materials. J. Mater. Chem. 2005, 15, 3787-3811. [CrossRef]

20. Günes, S.; Neugebauer, H.; Sariciftci, N.S. Conjugated Polymer-Based Organic Solar Cells. Chem. Rev. 2007, 107, 1324-1338. [CrossRef] [PubMed]

21. Ansari, M.A.; Mohiuddin, S.; Kandemirli, F.; Malik, M.I. Synthesis and characterization of poly(3-hexylthiophene):improvement of regioregularity and energy band gap. RSC Adv. 2018, 8, 8319-8328. [CrossRef]

22. Holliday, S.; Ashraf, R.S.; Wadsworth, A.; Baran, D.; Yousaf, S.A.; Nielsen, C.B.; Tan, C.H.; Dimitrov, S.D.; Shang, Z.; Gasparini, N.; et al. High-efficiency and air-stable P3HT-based polymer solar cells with a new non-fullerene acceptor. Nat. Commun. 2016, 7, 11585. [CrossRef]

23. Jeong, Y.J.; Song, J.H.; Jeong, S.; Baik, S.J. PbS Colloidal Quantum Dot Solar Cells With Organic Hole Transport Layers for Enhanced Carrier Separation and Ambient Stability. IEEE J. Photovolt. 2018, 8, 2784766. [CrossRef]

24. Xu, W.; Peng, H.; Zhu, T.; Yi, C.; Gong, X. A solution-processed near-infrared polymer:PbS quantum dot photodetectors. RSC Adv. 2017, 7, 34633. [CrossRef]

25. Firdaus, Y.; Vandenplas, E.; Khetubol, A.; Cheyns, D.; Gehlhaar, R.; Van der Auweraer, M. Charge transport and recombination in P3HT:PbS solar cells. J. Appl. Phys. 2015, 117, 095503. [CrossRef]

26. Sun, Z.; Li, J.; Yan, F. Highly sensitive organic near-infrared phototransistors based on poly(3-hexylthiophene) and PbS quantum dots. J. Mater. Chem. 2012, 22, 21673-21678. [CrossRef]

27. Yu, G.; Heeger, A.J. Charge separation and photovoltaic conversion in polymer composites with internal donor/acceptor heterojunctions. J. Appl. Phys. 1995, 78, 4510-4515. [CrossRef]

28. Thomas, A.; Vinayakan, R.; Ison, V.V. An inverted ZnO/P3HT:PbS bulk-heterojunction hybrid solar cell with a CdSe quantum dot interface buffer layer. RSC Adv. 2020, 10, 16693-16699. [CrossRef]

29. Yang, D.; Zhou, Q. Solution-processed P3HT:PbS based NIR Photodetector with FET Configuration. IEEE Photonics Technol. Lett. 2020, 32, 19260716. [CrossRef] 